\title{
A cross-sectional study on associations of physical symptoms, health self-efficacy, and suicidal ideation among Chinese hospitalized cancer patients
}

Qingyi Xu', Shuhua Jia', Maiko Fukasawa ${ }^{1}$, Lin Lin ${ }^{3}$, Jun $\mathrm{Na}^{4}$, Zhen $\mathrm{Mu}^{1}, \mathrm{Bo} \mathrm{Li}^{5}$, Ningning Li ${ }^{6}$, Tong Zhao ${ }^{7}$, Zaishuang Ju', Meng $\mathrm{He}^{8}$, Lianzheng $\mathrm{Yu}^{4}$, Norito Kawakami ${ }^{2}$, Yuejin $\mathrm{Li}^{9}$ and Chao Jiang ${ }^{1 *}$

\begin{abstract}
Background: Epidemiological studies have shown increased risk of suicide in cancer patients compared with the general population. The present study aimed to examine the association between physical symptoms and suicidal ideation in Chinese hospitalized cancer patients and test the modifying effect of health self-efficacy on the association.

Methods: A cross-sectional study was conducted with 544 hospitalized cancer patients in two general hospitals in northeast China via face-to-face interviews. Suicidal ideation was measured by using the first four items on the Yale Evaluation of Suicidality scale and then dichotomized into a positive and negative score. Multivariate logistic regression analyses were conducted to examine the impacts of physical symptoms, health self-efficacy, and their interactions on suicidal ideation.

Results: The suicidal ideation rate was $26.3 \%$ in the enrolled cancer patients. Logistic regression showed that insomnia $(a \mathrm{ar}=1.84,95 \% \mathrm{Cl} 1.13$ to $3.00, p=0.015)$ and lack of appetite $(\mathrm{aOR}=2.14,95 \% \mathrm{Cl} 1.26$ to $3.64, p=0.005)$ were significantly associated with suicidal ideation. Low health self-efficacy had a marginally significant exaggerating effect on the association between pain and suicidal ideation $(\mathrm{aOR}=2.77,95 \% \mathrm{Cl} 0.99$ to $7.74, p=$ 0.053), after adjusting for significant socio-demographics, clinical characteristics, and depression.

Conclusions: These findings demonstrate significant associations between physical symptoms (insomnia and/or lack of appetite) and suicidal ideation and highlight the potential modifying role of health self-efficacy in the identification and prevention of suicide among cancer patients.
\end{abstract}

Keywords: Suicidal ideation, Cancer, Physical symptoms, Self-efficacy

\footnotetext{
* Correspondence: jiangchaowst@hotmail.com

'Department of Psychology, College of Humanities and Social Sciences, Dalian Medical University, Dalian, China

Full list of author information is available at the end of the article
}

(c) The Author(s). 2020 Open Access This article is licensed under a Creative Commons Attribution 4.0 International License, which permits use, sharing, adaptation, distribution and reproduction in any medium or format, as long as you give appropriate credit to the original author(s) and the source, provide a link to the Creative Commons licence, and indicate if changes were made. The images or other third party material in this article are included in the article's Creative Commons licence, unless indicated otherwise in a credit line to the material. If material is not included in the article's Creative Commons licence and your intended use is not permitted by statutory regulation or exceeds the permitted use, you will need to obtain permission directly from the copyright holder. To view a copy of this licence, visit http://creativecommons.org/licenses/by/4.0/ The Creative Commons Public Domain Dedication waiver (http://creativecommons.org/publicdomain/zero/1.0/) applies to the data made available in this article, unless otherwise stated in a credit line to the data. 


\section{Background}

Cancer is a leading cause of death worldwide [1]. The diagnosis of cancer and the subsequent treatments may evoke psychological and physical distresses in patients, which affects life quality and even the will to live [2-4]. Suicide rate among cancer patients is generally twice as high as that of the general population $[5,6]$. Prior suicidal ideation (SI) is one of the primary risk factors for future suicidal behaviors [7,8] and $60 \%$ of the first suicide attempts occur within a year of SI onset [9]. Therefore, early detection of SI in cancer patients is critical for reducing the incidence of suicide and suicide attempts.

It has been reported that up to $71 \%$ of cancer patients have reported SI in clinical settings [10]. The possible risk factors for SI include female gender [11], old age [12], unmarried status [13, 14], retirement [15], recurrence [2], cancer metastasis [2, 16], mental disorders [17] and pain [18-20]. Mental illnesses such as depressive disorders are known to be a significant predictor for SI $[4,15,16]$. However, it is very challenging for oncologists to diagnose depression due to the complexities involved in conducting depression-related clinical interviews. Additionally, although SI is a diagnostic criterion of depression, depression is not an essential precondition for SI to occur [21]; in other words, one may have SI without any diagnosable depression. Physical complaints such as insomnia and appetite loss that are commonly observed in patients with cancer [22] also serve as diagnostic criteria for several mental disorders, e.g. depressive disorders. Therefore, it is of great interest to investigate whether such physical symptoms increase the risk of SI in both populations with or without depressive disorders.

There has been growing evidence that persistent poor physical status significantly increases the risk of suicidal thoughts in cancer patients [4, 18, 22-24]. A study on 48 cancer patients with metastasis revealed that the burden of physical symptoms is more correlated with desire for death than pain or depression [22]. However, the effect of physical status on SI has drawn relatively little attention compared with other psychiatric symptoms. Most studies either analyzed the association between numbers/sum-score of physical symptoms and SI or just focused on pain as the main risk factor [11, 18, 19, 25]. To the best of our knowledge, so far, there has been only one study that investigated the association between individual physical symptoms (i.e. diarrhea, hair loss, usual fatigue) and SI, however, this study only focused on patients with stomach cancer in South Korea [23]. An analysis of specific symptoms offers opportunities to identify physical indicators for SI whereas prior studies summing symptoms may miss important information [26]. Therefore, it is valuable to investigate whether each specific physical symptom is associated with SI, which would improve early detection of the potential suicide risk in cancer patients.

Expressions of depression vary across different cultures [27]. It has been reported that Asians express more physical symptoms than Westerners when experiencing depression, while the latter prone to express cognitive and psychological symptoms [27, 28]. Thus, the association between physical symptoms and SI may be different in Asian countries, e.g. China, from that of western countries. However, there is a paucity of such studies on cancer patients in China.

Health self-efficacy, referring to individual's perceived ability to cope with stress and their self-confidence in overcoming challenges to their health $[29,30]$, has been demonstrated to play a critical role in pain management and health adjustment [31]. A previous study found that greater illness burden was significantly associated with lower health self-efficacy [32]. Moreover, emerging evidence suggests that low health self-efficacy increases the risk of suicide behaviors over the course from prior ideation to future intention [33, 34]. Therefore, health self-efficacy may have a modifying effect on the association between physical symptoms and SI. However, to the best of our knowledge, few studies have examined the potential modifying effect.

The present study aimed to examine the association between physical symptoms and SI in Chinese hospitalized cancer patients, and the potential modifying effect of health self-efficacy on this association. We hypothesized that: 1) physical symptoms are associated with an increased risk for SI, even after controlling for established predictors; 2) the association between physical symptoms and SI is greater for patients with low levels of health self-efficacy, compared to those with high levels.

\section{Methods \\ Participants and procedures}

The cross-sectional study was conducted in two general hospitals (the Second Affiliated Hospital of Dalian Medical University and the Zhongshan Affiliated Hospital of Dalian University) in Dalian, a metropolitan region located on the northeast coast of China. Dalian's gross domestic product (GDP) ranked 26th nationally in 2018, falling into the medium level among all the cities in China. Patients who were hospitalized in the oncology settings at the two hospitals were consecutively recruited from January to December 2015. Eligibility criteria included 1) diagnosis of cancer by pathology or cytology; 2) age of 18 years or older; 3) patient awareness of their own cancer diagnosis; 4) provision of written informed consent. Exclusion criteria were 1) inability to participate in the survey independently due to serious illness, 
cognitive impairment (such as dementia or delusions) or other medical conditions; 2) language communication barriers or lack of capability to cooperate in the interview; 3) family caregivers who required confidentiality of the cancer diagnosis from the patient. All the procedures were approved by the Committee on Human Ethics of Dalian Medical University. All enrolled patients signed the written informed consent.

Trained research staff conducted the interview after the patients had undergone at least 3 days of clinical treatments. We asked whether they were bothered by each of fourteen physical symptoms over the previous 2 days in the interview. The face-to-face interviews lasted $40-50 \mathrm{~min}$. All the measures were verbally administered to enhance data accuracy and reduce the frequency of missing data. Cancer-related clinical information, i.e. type of cancer, stage at diagnosis, medical treatment, and metastatic status, were extracted from the patients' medical records.

\section{Measures \\ Suicidal ideation}

The Yale Evaluation of Suicidality scale is a 16-item structured questionnaire that assesses current suicidal thoughts and actions, history of suicide attempts, and feelings/attitudes on suicide [35]. It has demonstrated adequate validity in cancer patients $[3,35]$ (see Additional file 1). The first four items in the questionnaire compose a screening measure that assesses the strength of the patients' wish to live and wish to die (passive SI), the existence of thoughts of killing himself/herself (active SI), and the weighing of dying over living. Because of the rarity with which any suicidality was endorsed, all four screening items were used to assess SI in this study (Cronbach's $\alpha=0.93)$. Aiming to detect both clear and potential suicidal thoughts, we dichotomized the patients' scores, where a positive screen (endorsement of any of the four items) $=1$ and a negative screen $=0$.

\section{Independent variables and covariates}

Physical symptoms were measured with one item from the McGill Quality of Life Questionnaire (MQOL) [36]. Participants were asked whether they were bothered by each of 14 symptoms over the previous 2 days with a response of yes and no. Fourteen items were included: pain, shortness of breath, insomnia, weakness, fatigue, nausea, lack of appetite, constipation, diarrhea, edema, cough, vomiting, fever, and bloating.

\section{Health self-efficacy}

We measured health self-efficacy by using the Chinese version of the Strategies Used by People to Promote Health (SUPPH) [37], a 29-item validated scale including three dimensions. Each item is rated on a five-point scale ranging from "little confidence" $=1$ to "quite a lot of confidence" $=5$. All the items were summed into a score with a higher score indicating a higher sense of health self-efficacy. To evaluate the relative risk of SI, the scores were categorized into high $(\geq 50)$ and low groups $(<50)$ by the median. The Cronbach's $\alpha$ of the present data was 0.96 .

\section{Depression}

Clinical diagnosis of depression was evaluated by the 17 item version of the Hamilton Depression Rating Scale (HDRS-17) that assesses the severity of depression symptoms over the past week [38]. It contains 17 items to detect depressive disorders and identifies the severity classification by semi-structured interview. A higher total score indicates a greater severity of depression. Severity classifications are defined as follows: $0-7$ for no depression, 8-16 for mild depression, 17-23 for moderate depression, and $\geq 24$ for severe depression. According to the proposal by Zimmerman et al. [39], we used the cut-off value of 8 to identify depressive disorders, which showed satisfying reliability (Cronbach's $\alpha=0.84$; Split reliability $=0.79$ ).

\section{Other variables}

Socio-demographic characteristics included sex, age, marital status, education, residence, employment status, household income, smoking, and drinking. Cancerrelated clinical variables included cancer type, stage at diagnosis, medical treatment, time since diagnosis, and metastasis status.

\section{Statistical analysis}

Descriptive analyses and chi-square were used to compare the socio-demographics and clinical variables between the cancer patients with and without SI. Multivariate logistic regression was conducted to determine the associations between physical symptoms and SI with three models.

We also tested the interaction of health self-efficacy and each physical symptom on SI using multivariate regression analysis. The ratios were adjusted for potential confounding factors to SI, which included socio-demographics, clinical characteristics, and diagnosed depression. All statistical analyses were performed by using IBM SPSS version 21.0. The reported CIs were calculated at the $95 \%$ and the statistical significance was set at 0.05 level. All tests were two-sided.

\section{Results}

\section{Sample characteristics}

A total of 700 cancer patients were contacted for this study. Among them, 59 eligible patients refused to join and 69 patients were not able to cooperate due to at 
least one of the following factors: poor physical conditions, poor mental health conditions, and low education level. Initially, 282 out of 350 eligible hospitalized patients from Zhongshan Affiliated hospital of Dalian University (response rate $80.6 \%$ ), and 290 out of 350 from Second hospital of Dalian Medical University (response rate $82.9 \%$ ) agreed to participate in the study, however, 28 of them failed to complete the questionnaire and dropped out in the halfway. As a result, a total of 544 patients were included in the analysis (valid rate 95.1\%). The sample characteristics are displayed in Table 1. The sample consisted of both male (49.2\%) and female $(51.8 \%)$ patients, approximately male:female $=1: 1$, at average age of 59.9 years (range,19-81 years old; standard deviation, 11.6 years). The majority (78.3\%) primarily lived in the cities. Over $70 \%$ of the participants were clustered into three types of cancers: digestive system cancer (29\%), lung cancer (23.7\%), breast cancer (18.9\%). The rest were diagnosed with gynecological cancers (9.6\%), brain and neck cancers (6.4\%), leukemia/lymphoma (5.9\%), and others (6.4\%). About half of the participants had metastasis and diagnosed with cancer for more than 1 year. The percentage of missing data was less than $1.5 \%$ for all variables and missing data on all variables except for SI was assumed to be in the low-risk category.

\section{Prevalence of suicidal ideation}

Out of the total participants $(n=544)$, over a quarter of them reported that they had experienced SI. The prevalence of SI was $26.3 \%(n=143)$, with $24.4 \%$ in men and $28.0 \%$ in women.

\section{Study factors associated with suicidal ideation}

The comparison of socio-demographic factors and the related clinical characteristics between the enrolled patients with and without SI is displayed in Table 2. We found no significant difference in the following demographic variables: sex, age, education attainment, or household income between the two groups (all $p>0.05$ ). A significant difference was found with marital status, employment status, metastasis, and currently diagnosed depression (all $p<0.05$ ). The comparison of the stage at diagnosis showed a marginal $p$ value $(p=0.051)$. In addition, the two groups of patients presented significantly different levels of health self-efficacy and profiles of physical symptoms, in particular, symptoms like pain, shortness of breath, insomnia, nausea, and lack of appetite. Based on these results, we entered sociodemographic factors, metastasis, stage at diagnosis, and depression as control variables in the subsequent analyses.
Table 1 Characteristics of the sample $(N=544)$

\begin{tabular}{|c|c|c|}
\hline & $\mathbf{N}$ & $\%$ \\
\hline \multicolumn{3}{|l|}{ Sex } \\
\hline Men & 262 & 48.2 \\
\hline Women & 282 & 51.8 \\
\hline \multicolumn{3}{|l|}{ Age (years) } \\
\hline $18-49$ & 82 & 15.1 \\
\hline $50-64$ & 282 & 51.8 \\
\hline $65+$ & 180 & 33.1 \\
\hline \multicolumn{3}{|l|}{ Marital status } \\
\hline Married & 433 & 79.6 \\
\hline Separated, divorced, bereaved & 85 & 15.6 \\
\hline Never married & 26 & 4.8 \\
\hline \multicolumn{3}{|l|}{ Education } \\
\hline Less than high school & 269 & 49.4 \\
\hline High school & 143 & 26.3 \\
\hline College or higher & 132 & 24.3 \\
\hline \multicolumn{3}{|l|}{ Residence } \\
\hline City & 426 & 78.3 \\
\hline Rural & 118 & 21.7 \\
\hline \multicolumn{3}{|l|}{ Employment status } \\
\hline Employed & 99 & 18.2 \\
\hline Unemployed & 47 & 8.6 \\
\hline Retired & 343 & 63.1 \\
\hline Farm work & 50 & 9.2 \\
\hline Other & 5 & 0.9 \\
\hline \multicolumn{3}{|l|}{ Cancer diagnosis } \\
\hline Digestive tract & 158 & 29.0 \\
\hline Lung & 129 & 23.7 \\
\hline Breast & 103 & 18.9 \\
\hline Gynecologic & 52 & 9.6 \\
\hline Brain and Neck & 35 & 6.4 \\
\hline Leukemia/Lymphoma & 32 & 5.9 \\
\hline Other & 35 & 6.4 \\
\hline \multicolumn{3}{|l|}{ Stage at diagnosis } \\
\hline । & 52 & 9.6 \\
\hline$\|$ & 108 & 19.9 \\
\hline III & 163 & 30.0 \\
\hline IV & 217 & 39.9 \\
\hline Unknown & 4 & 0.7 \\
\hline \multicolumn{3}{|l|}{ Time since diagnosis } \\
\hline Less than 3 months & 123 & 22.6 \\
\hline 4-12 months & 148 & 27.2 \\
\hline 13-36 months & 156 & 28.7 \\
\hline More than 36 months & 117 & 21.5 \\
\hline Metastasis present & 296 & 54.4 \\
\hline
\end{tabular}


Table 2 Characteristics of Cancer patients with and without Suicidal Ideation ( $N=544)$

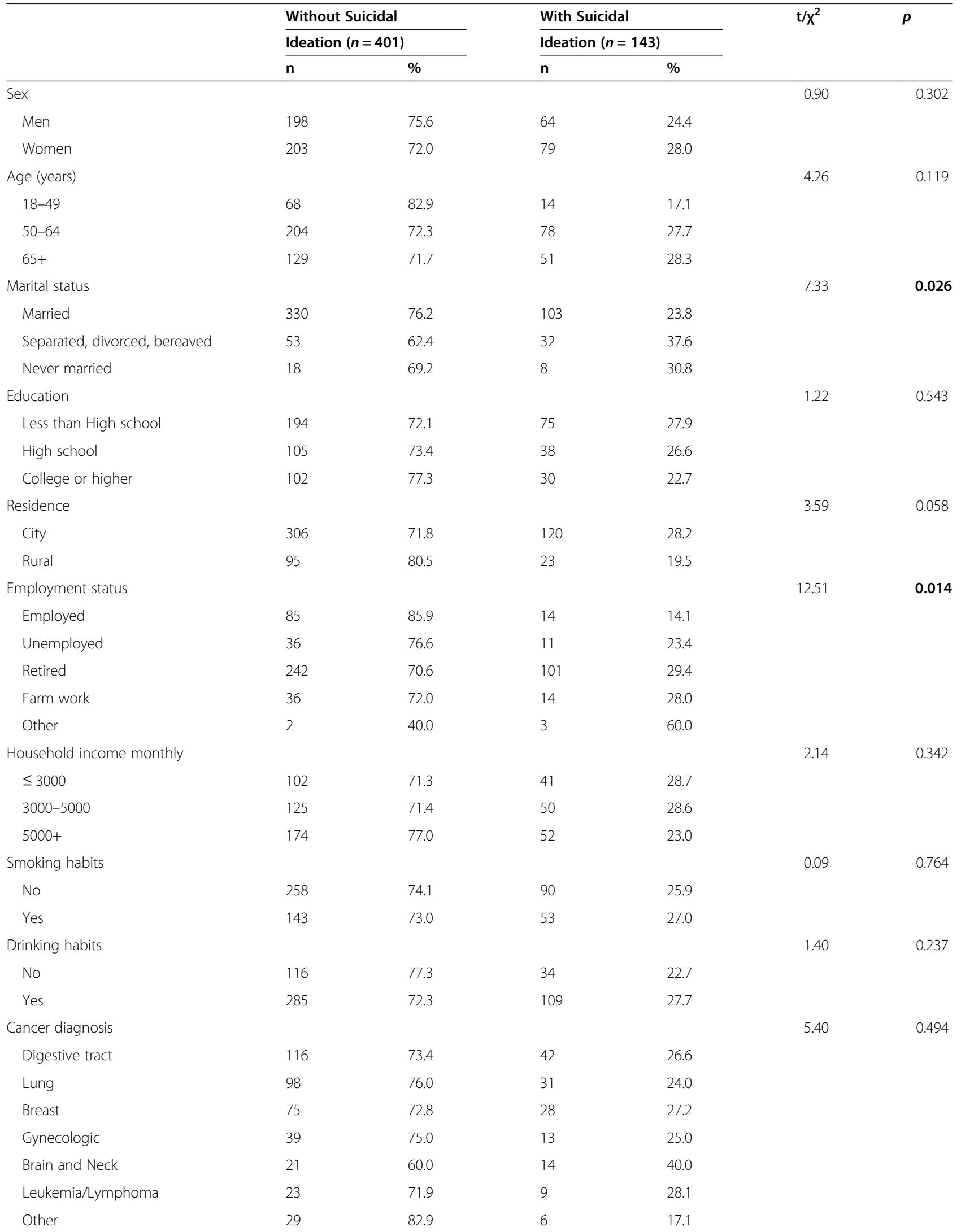


Table 2 Characteristics of Cancer patients with and without Suicidal Ideation ( $N=544)$ (Continued)

\begin{tabular}{|c|c|c|c|c|c|c|}
\hline & \multirow{2}{*}{\multicolumn{2}{|c|}{$\begin{array}{l}\text { Without Suicidal } \\
\text { Ideation }(n=401)\end{array}$}} & \multirow{2}{*}{\multicolumn{2}{|c|}{$\frac{\text { With Suicidal }}{\text { Ideation }(n=143)}$}} & \multirow[t]{3}{*}{$t / x^{2}$} & \multirow[t]{3}{*}{$p$} \\
\hline & & & & & & \\
\hline & $\mathrm{n}$ & $\%$ & $\mathrm{n}$ & $\%$ & & \\
\hline Stage of cancer & & & & & 9.44 & 0.051 \\
\hline । & 39 & 75.0 & 13 & 25.0 & & \\
\hline$\|$ & 78 & 72.2 & 30 & 27.8 & & \\
\hline III & 132 & 81.0 & 31 & 19.0 & & \\
\hline IV & 148 & 68.2 & 69 & 31.8 & & \\
\hline Unknown & 4 & 100.0 & 0 & 0.0 & & \\
\hline Medical treatment, ever & & & & & 9.03 & 0.108 \\
\hline Surgery only & 40 & 81.6 & 9 & 18.4 & & \\
\hline Radion \& Surgery + Radion & 11 & 52.4 & 10 & 47.6 & & \\
\hline Chemo \& Surgery+Chemo & 297 & 75.2 & 98 & 24.8 & & \\
\hline Chemo+ Radion & 12 & 66.7 & 6 & 33.3 & & \\
\hline Surgery+Chemo+ Radion & 33 & 68.8 & 15 & 31.3 & & \\
\hline None of above & 8 & 61.5 & 5 & 38.5 & & \\
\hline Metastasis & & & & & 8.83 & 0.003 \\
\hline No & 198 & 79.8 & 50 & 20.2 & & \\
\hline Yes & 203 & 68.6 & 93 & 31.4 & & \\
\hline Depression & & & & & 98.27 & $<0.001$ \\
\hline None & 381 & 80.9 & 90 & 19.1 & & \\
\hline Mild & 19 & 31.1 & 42 & 68.9 & & \\
\hline Moderate or Serious & 1 & 8.3 & 11 & 91.7 & & \\
\hline Physical symptoms & & & & & & \\
\hline Pain & 130 & 65.3 & 69 & 34.7 & 11.39 & 0.001 \\
\hline Shortness of breath & 51 & 60.7 & 33 & 39.3 & 8.66 & 0.003 \\
\hline Insomnia & 106 & 64.2 & 59 & 35.8 & 10.96 & 0.001 \\
\hline Weakness & 127 & 69.8 & 55 & 30.2 & 2.35 & 0.077 \\
\hline Fatigue & 100 & 71.4 & 40 & 28.6 & 0.57 & 0.258 \\
\hline Nausea & 26 & 59.1 & 18 & 40.9 & 5.28 & 0.02 \\
\hline Lack of appetite & 60 & 57.1 & 45 & 42.9 & 18.44 & $<0.001$ \\
\hline Constipation & 74 & 68.5 & 34 & 31.5 & 1.88 & 0.107 \\
\hline Diarrhea & 29 & 74.4 & 10 & 25.6 & 0.01 & 0.547 \\
\hline Edema & 28 & 75.7 & 9 & 24.3 & 0.08 & 0.476 \\
\hline Cough & 64 & 71.1 & 26 & 28.9 & 0.38 & 0.311 \\
\hline Vomiting & 11 & 61.1 & 8 & 44.4 & 2.54 & 0.095 \\
\hline Fever & 6 & 60.0 & 4 & 40.0 & 0.99 & 0.253 \\
\hline Bloated & 49 & 71.0 & 20 & 29.0 & 0.30 & 0.342 \\
\hline Health Self-efficacy Score & & & & & 65.43 & $<0.001$ \\
\hline $\operatorname{High}(\geq 50)$ & 261 & 87.6 & 37 & 12.4 & & \\
\hline $\operatorname{Low}(<50)$ & 140 & 56.9 & 106 & 43.1 & & \\
\hline
\end{tabular}

Bold face $p<0.05$

Effects of physical symptoms on suicidal ideation

Multivariate logistic regression analysis was performed to examine the effect of each physical symptoms on SI, individually. We focused on the six physical symptoms (pain, shortness of breath, insomnia, nausea, weakness, and lack of appetite) that were identified with significant 
Table 3 Multivariate Logistic Regression Analyses for Predictive Factors of Suicidal Ideation in Cancer Patients. $(N=544)$

\begin{tabular}{|c|c|c|c|c|c|c|c|c|c|c|c|c|}
\hline \multirow[t]{2}{*}{ Characteristics } & \multicolumn{4}{|c|}{ Model 1} & \multicolumn{4}{|c|}{ Model 2} & \multicolumn{4}{|c|}{ Model 3} \\
\hline & $\mathrm{aOR}$ & $95 \mathrm{Cl}$ & & $p$ & aOR & $95 \mathrm{Cl}$ & & $p$ & aOR & $95 \% \mathrm{C}$ & & $p$ \\
\hline \multicolumn{13}{|l|}{ Physical symptoms } \\
\hline pain & 1.62 & 1.06 & 2.47 & 0.026 & 1.33 & 0.84 & 2.08 & 0.223 & 1.11 & 0.69 & 1.79 & 0.659 \\
\hline shortness of breath & 1.37 & 0.79 & 2.36 & 0.265 & 1.52 & 0.85 & 2.73 & 0.157 & 1.47 & 0.80 & 2.72 & 0.218 \\
\hline insomnia & 2.10 & 1.34 & 3.27 & 0.001 & 2.00 & 1.25 & 3.19 & 0.004 & 1.84 & 1.13 & 3.00 & 0.015 \\
\hline weakness & 1.03 & 0.66 & 1.61 & 0.901 & 0.95 & 0.59 & 1.52 & 0.826 & 0.88 & 0.54 & 1.44 & 0.603 \\
\hline nausea & 1.56 & 0.76 & 3.20 & 0.223 & 1.20 & 0.57 & 2.53 & 0.636 & 0.95 & 0.43 & 2.10 & 0.891 \\
\hline lack of appetite & 2.51 & 1.56 & 4.04 & $<0.001$ & 2.38 & 1.43 & 3.94 & 0.001 & 2.14 & 1.26 & 3.64 & 0.005 \\
\hline \multicolumn{13}{|l|}{ Health Self-efficacy Score } \\
\hline Low(<50)vs. High $(\geq 50)$ & & & & & 4.98 & 3.11 & 7.97 & $<0.001$ & 3.51 & 2.13 & 5.80 & $<0.001$ \\
\hline
\end{tabular}

Bold face $p<0.05$

aOR (95Cl) Adjusted Odds Ratio (95\% Confidence Interval)

Model 1\& Model 2: Adjusted for demographic and clinical variables including sex, age, marital status, education attainment, employment, metastasis, stage at diagnosis

Model 3: Additionally adjusted diagnosed depression

or marginally significant differences in the earlier comparison between the participants with or without SI. Both insomnia $(\mathrm{aOR}=1.84,95 \% \mathrm{CI} 1.13$ to 3.00 , $p=0.015)$ and lack of appetite $(\mathrm{aOR}=2.14,95 \% \mathrm{CI}$ 1.26 to $3.64, p=0.005)$ were found positively associated with SI after adjusting for socio-demographics, clinical variables, and diagnosed depression in model 3 (Table 3).
Interaction of health self-efficacy and physical symptoms on suicidal ideation

We also tested the modifying effect of health selfefficacy on the association between physical symptoms and SI. As shown in Table 4, physical symptoms of insomnia and lack of appetite were significantly associated with SI in patients with low levels of health self-efficacy. According to a difference in OR between high and low

Table 4 Association between physical symptoms, health self-efficacy, and suicidal ideation $(N=544)$

\begin{tabular}{|c|c|c|c|c|c|c|c|c|c|c|c|c|}
\hline \multirow{2}{*}{$\begin{array}{l}\text { Physical symptoms and self- } \\
\text { efficacy }\end{array}$} & \multicolumn{4}{|c|}{ Model 1} & \multicolumn{4}{|c|}{ Model 2} & \multicolumn{4}{|c|}{ Model 3} \\
\hline & $\mathrm{aOR}$ & \multicolumn{2}{|l|}{$95 \mathrm{Cl}$} & $p$ & aOR & \multicolumn{2}{|l|}{$95 \mathrm{Cl}$} & \multirow[t]{2}{*}{$p$} & \multirow[t]{2}{*}{$\mathrm{aOR}$} & \multicolumn{2}{|c|}{$95 \% \mathrm{Cl}$} & \multirow[t]{2}{*}{$p$} \\
\hline \multicolumn{10}{|l|}{ High-level of health SE (score $\geq 50$ ) } & & & \\
\hline Pain & 0.68 & 0.29 & 1.56 & 0.358 & 0.62 & 0.26 & 1.48 & 0.279 & 0.60 & 0.24 & 1.45 & 0.252 \\
\hline Shortness of breath & 1.29 & 0.48 & 3.49 & 0.617 & 1.41 & 0.51 & 3.91 & 0.508 & 1.39 & 0.50 & 3.88 & 0.533 \\
\hline Insomnia & 2.04 & 0.91 & 4.58 & 0.083 & 2.01 & 0.87 & 4.64 & 0.102 & 1.87 & 0.79 & 4.44 & 0.063 \\
\hline Weakness & 0.78 & 0.34 & 1.81 & 0.563 & 0.83 & 0.35 & 2.00 & 0.679 & 0.82 & 0.34 & 1.98 & 0.661 \\
\hline Nausea & 0.53 & 0.06 & 4.75 & 0.572 & 0.37 & 0.04 & 3.49 & 0.382 & 0.73 & 0.03 & 3.29 & 0.344 \\
\hline Lack of appetite & 2.35 & 0.99 & 5.59 & 0.052 & 2.47 & 1.01 & 6.04 & 0.047 & 2.44 & 0.99 & 6.00 & 0.052 \\
\hline \multicolumn{13}{|c|}{ Interaction between physial symptoms and health $\mathrm{SE}^{\mathrm{a}}$} \\
\hline Health SE x Pain & 3.21 & 1.20 & 8.59 & 0.02 & 3.03 & 1.12 & 8.15 & 0.028 & 2.77 & 0.99 & 7.74 & 0.053 \\
\hline Health SE x Shortness of breath & 1.73 & 0.52 & 5.77 & 0.372 & 1.79 & 0.54 & 5.97 & 0.346 & 1.82 & 0.52 & 6.42 & 0.351 \\
\hline Health SE x Insomnia & 0.95 & 0.37 & 2.44 & 0.906 & 0.98 & 0.38 & 2.55 & 0.968 & 1.05 & 0.39 & 2.81 & 0.931 \\
\hline Health SE x Weakness & 1.60 & 0.59 & 4.29 & 0.355 & 1.59 & 0.59 & 4.30 & 0.36 & 1.52 & 0.54 & 4.23 & 0.427 \\
\hline Health SE x Nausea & 5.84 & 0.57 & 59.61 & 0.137 & 6.02 & 0.60 & 60.74 & 0.128 & 6.24 & 0.53 & 73.16 & 0.145 \\
\hline Health SE x Lack of appetite & 1.03 & 0.37 & 2.89 & 0.959 & 1.07 & 0.38 & 3.05 & 0.895 & 1.03 & 0.35 & 3.01 & 0.964 \\
\hline
\end{tabular}

SE self-efficacy

Bold face $p<0.05$

aOR (95Cl) Adjusted Odds Ratio (95\% Confidence Interval)

Model 1: Adjusted for sex, age, marital status, education attainment, employment and all the other physical sym ptoms

Model 2: Additionally adjusted for clinical variables: metastasis, stage at diagnosis

Model 3: Additionally adjusted for diagnosed depression

${ }^{a}$ The interaction between a physical symptom and health self-efficacy (high /low) was tes ted indivi dually 
health self-efficacy, two-way interaction terms of health self-efficacyxeach physical symptom were entered and tested individually. In model 3 , low health self-efficacy showed a marginally significant exaggerating effect on the association between pain and SI $(\mathrm{aOR}=2.77,95 \% \mathrm{CI}$ 0.99 to $7.74, p=0.053$ ) when adjusted for all the confounding variables.

Because the depression-rating scale HDRS-17 also contains items related to the physical symptoms (i.e. sleep, weight loss, and suicide), which may confound the measures, we then performed another set of analyses by using the HDRS-12 scores that excluded the evaluation of the aforementioned physical symptoms in the depression variable. The results agreed with our previous findings, as shown in the Additional file 2 (Model 3 in Appendix Table $3 \&$ Table 4) with the data of insomnia $(\mathrm{aOR}=1.75,95 \%$ CI 1.07 to $2.87, p=0.026)$, lack of appetite $(\mathrm{aOR}=2.20,95 \%$ CI 1.29 to $3.74, p=0.004)$, and low health self-efficacy $\times$ pain $(\mathrm{aOR}=2.68,95 \% \mathrm{CI} 0.96$ to $7.47, p=0.056$ ).

\section{Discussion}

Overall, our study revealed that the prevalence of SI was 26.3\% among Chinese hospitalized cancer patients. Patients with physical symptoms of insomnia or lack of appetite were more likely to report SI, even after adjusted for socio-demographic variables (marital status, being retired), clinical variables (stage at diagnosis, metastasis), and diagnosed depression. Furthermore, our findings suggest a marginally exaggerating effect of low health self-efficacy on pain and SI, after adjusted for all the confounding variables.

In the present study, $26.3 \%$ of the hospitalized patients reported SI following cancer diagnosis, which is higher than the previous reports $(15.3-18.4 \%)$ on the cancer population in Mainland China [25, 40, 41]. Such prevalence is comparable to the previous studies conducted in Spain, the U.S., and Taiwan (22.6-29.5) [4, 13, 15], but higher than that of some Western studies (7.8-17.7\%) $[14,17-20]$ and much lower than that of Japan and South Korea (34.7-71\%) [23, 42-44]. The discrepancy between the reported studies and ours may result from the differences in measures and sample composition. The majority of the patients participating in our study were diagnosed with cancers of the digestive system, breast, and lung. Those with stage III and IV cancers accounted for $70 \%$ of the total samples. It has been reported that the cancer site and stage at diagnosis are associated with SI [14, 44]. Moreover, the scale utilized in our study includes both passive and active SI as the outcome. The passive SI refers to the death ideation as a wish to die or preference to die and the active SI refers to thoughts of killing oneself [45]; when both are included in the analysis, it may show a higher prevalence.
To the best of our knowledge, this is the first study to examine the associations of physical symptoms, health self-efficacy and SI, and their interactions on SI among cancer patients. In line with our hypothesis, we found that patients with specific physical symptoms (i.e. lack of appetite, insomnia) were more likely to report SI. Lack of appetite was about twice as likely to be associated with SI after adjusted for socio-demographic and clinical characteristics. Choi et al. also found physical symptoms were significantly associated with SI in stomach cancer patients [23]. Previous studies showed that patients with difficulties in vital function, e.g. eating, experienced more helplessness/hopelessness and were therefore at higher risk of SI [24, 44]. Our observed association between insomnia and SI is also biologically plausible. Sleeping loss causes various endocrine and immunological changes and studies have shown that dysfunction of serotonin (5-hydroxytriptamine) plays a significant role in suicide [46]. Insufficient sleep negatively impacts cognitive function resulting in poor judgment and deficits in impulse control, which might contribute to SI and suicidal behaviors [47]. Moreover, insomnia is not only a diagnostic criterion of depression but also strongly associated with co-occurring mental disorders [48] that increase the risk for suicidality.

The results support our second hypothesis, indicating that low health self-efficacy has a marginally significant exaggerating effect on the association between pain and SI, after adjusting for socio-demographic, clinical, and depression variables. The finding agrees with previous studies, in which patients with comparable levels of pain tend to have less depressive symptoms if they have higher health self-efficacy [49]. Health self-efficacy reflects an individual's perceived ability to cope with stress and confidence in overcoming challenges to their health $[29,30]$. There is evidence that cancer patients with perceived higher health self-efficacy reported lower psychological distress and higher quality of life [31]. In contrast, patients with low health self-efficacy may prematurely terminate coping efforts, consider escaping from the distressing situations, and think of suicide.

There are some limitations in our study. First, our sample is from the oncology settings of two general hospitals in northeast China, so the results may limit generalization to outpatient settings, cancer-specialized hospitals, or other regions of China. Second, the study respondents may have not reported SI due to stigma or embarrassment about suicide behaviors, thus the prevalence of SI reported in our study might be an underestimation. Third, the patients who refused to participate or failed to complete the interview may experience severe physical or emotional distress, which would result in a selection bias as we did not compare the sociodemographics between the participants who completed 
the survey and those who dropped out. Fourth, our study assessed the physical symptoms over the 2 days prior to the interview, which probably included the occasional or coincidental symptoms that might not be persistently associated with cancer. Fifth, instead of using the continuous HRSD-17 scores, our study used a cut-off score to dichotomize the variable of depression. Sixth, apart from depressive disorders, we did not identify other mental disorders in analyzing the predictors for SI. Finally, a cross-sectional study is not able to determine a cause-effect relationship. Future longitudinal research is needed to explore whether health selfefficacy interventions reduce the incidence of SI and further risks of suicide, e.g. future intent or prior suicide attempts.

One in four hospitalized cancer patients in our study reported SI, indicating that high risk of suicidality remains an issue for this population in China. The present study provides valuable potential implications with respect to the care of cancer patients:1) Paying attention to physical symptoms, especially insomnia and lack of appetite, would help with the early identification of SI and thus prevent suicide; 2) Actively managing the physical symptoms via medical and psychological treatments would decrease the risks of suicide; 3) Promoting a sense of health self-efficacy could play a key role in suicide prevention, particularly for the cancer patients presenting with pain.

\section{Conclusions}

The present study revealed significant associations between physical symptoms (i.e. insomnia, lack of appetite) and SI in cancer patients. Furthermore, health selfefficacy plays a modifying role in the relationship of pain and SI among Chinese hospitalized patients with cancer. Paying attention to these physical symptoms and promoting the sense of health self-efficacy could be helpful for healthcare professionals to detect high-risk patients for suicide early and thus enable timely interventions.

\section{Supplementary Information}

The online version contains supplementary material available at https://doi. org/10.1186/s12888-020-02945-x.

\section{Additional file 1.}

Additional file 2: Table 1 Multiple logistic regression analysis with the backward method in cancer patients. Table 2 Correlations between main variables $(n=544)$. Table 3. Multivariate Logistic Regression Analyses for Predictive Factors of Suicidal Ideation in Cancer Patients. $(N=544)$. Table 4. Association between physical symptoms, health self-efficacy, and suicidal ideation $(N=544)$.

\section{Abbreviations}

AOR: Adjusted odds ratio; Cl: Confidence intervals; SI: Suicidal ideation; YES: Yale Evaluation of Suicidality; MQOL: McGill Quality of Life Questionnaire;
SUPPH: Strategies Used by People to Promote Health; HDRS: Hamilton Depression Rating Scale; SE: Self-efficacy

\section{Acknowledgements}

We are grateful to all the medical staffs and patients in our study and to those who contributed to the clinical evaluation of the subjects.

\section{Authors' contributions}

QX wrote the manuscript as a first author. Professor CJ conceived and designed the study as a corresponding author. Professor NK, SJ, LL, and YL contributed to the interpretation of the analysis results and revised the manuscript. Professor NK, MF, and YL gave critical comments to this manuscript. Clinical oncology staff was involved in the collection of the data. All authors have read and approved the manuscript.

\section{Funding}

No funding was solicited or received for this manuscript.

\section{Availability of data and materials}

Data can be gained from the corresponding author.

\section{Ethics approval and consent to participate}

This study received ethical approval from the Committee on Human Ethics of Dalian Medical University and all research processes met ethical standards (No. 2019-11). Written informed content was obtained from the patients prior to the survey.

\section{Consent for publication}

Not applicable.

\section{Competing interests}

The authors declare that they have no competing interests.

\section{Author details}

${ }^{1}$ Department of Psychology, College of Humanities and Social Sciences, Dalian Medical University, Dalian, China. ${ }^{2}$ Department of Mental Health, the Graduate School of Medicine, the University of Tokyo, Tokyo, Japan. ${ }^{3}$ School of Psychology, Tianjin Normal University, Tianjin, China. ${ }^{4}$ Liaoning Provincial Center for Disease Control and Prevention, Institute of Chronic Disease, Shenyang, China. ${ }^{5}$ Department of Geriatrics, Guangzhou Brain Hospital, Guangzhou, China. ${ }^{6}$ Department of Psychology, Benxi Kangning Hospital, Benxi, China. ${ }^{7}$ Department of Oncology, Zhongshan Affiliated Hospital of Dalian University, Dalian, China. ${ }^{8}$ Department of Oncology, Second Affiliated Hospital of Dalian Medical University, Dalian, China. ${ }^{9}$ Department of Biology, Morgan State University, Baltimore, Maryland, USA.

Received: 4 April 2020 Accepted: 7 November 2020

Published online: 19 November 2020

\section{References}

1. Global Burden of Disease Cancer C, Fitzmaurice C, Allen C, Barber RM, Barregard L, Bhutta ZA, Brenner H, Dicker DJ, Chimed-Orchir O, Dandona R, et al. Global, Regional, and National Cancer Incidence, Mortality, Years of Life Lost, Years Lived With Disability, and Disability-Adjusted Life-years for 32 Cancer Groups, 1990 To 2015: a systematic analysis for the global burden of disease study. JAMA Oncol. 2017;3(4):524-48.

2. Lee SJ, Park JH, Park BY, Kim SY, Lee $I_{\text {, }}$ Kim JH, Koh DH, Kim CH, Park JH, Sohn MS. Depression and suicide ideas of cancer patients and influencing factors in South Korea. Asian Pac J Cancer Prev. 2014;15(7):2945-50.

3. Lehuluante A, Fransson P. Are there specific health-related factors that can accentuate the risk of suicide among men with prostate cancer? Support Care Cancer. 2014;22(6):1673-8.

4. Trevino KM, Abbott CH, Fisch MJ, Friedlander RJ, Duberstein PR, Prigerson HG. Patient-oncologist alliance as protection against suicidal ideation in young adults with advanced cancer. Cancer. 2014;120(15):2272-81.

5. Spoletini I, Gianni W, Caltagirone C, Madaio R, Repetto L, Spalletta G. Suicide and cancer: where do we go from here? Crit Rev Oncol Hematol. 2011; 78(3):206-19.

6. Dormer NR, McCaul KA, Kristjanson $\amalg$. Risk of suicide in cancer patients in Western Australia, 1981-2002. Med J Aust. 2008;188(3):140-3. 
7. Large M, Sharma S, Cannon E, Ryan C, Nielssen O. Risk factors for suicide within a year of discharge from psychiatric hospital: a systematic metaanalysis. Aust N Z J Psychiatry. 2011;45(8):619-28.

8. Allen MH, Abar BW, McCormick M, Barnes DH, Haukoos J, Garmel GM, Boudreaux ED. Screening for suicidal ideation and attempts among emergency department medical patients: instrument and results from the psychiatric emergency research collaboration. Suicide Life Threat Behav. 2013:43(3):313-23.

9. Kessler RC, Borges G, Walters EE. Prevalence of and risk factors for lifetime suicide attempts in the National Comorbidity Survey. Arch Gen Psychiatry. 1999:56(7):617-26.

10. Robson A, Scrutton F, Wilkinson L, MacLeod F. The risk of suicide in cancer patients: a review of the literature. Psychooncology. 2010;19(12): 1250-8.

11. Madeira N, Albuquerque E, Santos T, Mendes A, Roque M. Death ideation in cancer patients: contributing factors. J Psychosoc Oncol. 2011;29(6):636-42.

12. Akechi T, Okamura H, Kugaya A, Nakano T, Nakanishi T, Akizuki N, Yamawaki S, Uchitomi Y. Suicidal ideation in cancer patients with major depression. Jpn J Clin Oncol. 2000;30(5):221-4.

13. Fang CK, Chang MC, Chen PJ, Lin CC, Chen GS, Lin J, Hsieh RK, Chang YF, Chen $\mathrm{HW}$, Wu CL, et al. A correlational study of suicidal ideation with psychological distress, depression, and demoralization in patients with cancer. Support Care Cancer. 2014;22(12):3165-74.

14. Schneider KL, Shenassa E. Correlates of suicide ideation in a populationbased sample of cancer patients. J Psychosoc Oncol. 2008;26(2):49-62.

15. Diaz-Frutos D, Baca-Garcia E, Mahillo-Fernandez I, Garcia-Foncillas J, LopezCastroman J. Suicide ideation among oncologic patients in a Spanish ward. Psychol Health Med. 2016;21(3):261-71.

16. Trevino KM, Balboni M, Zollfrank A, Balboni T, Prigerson HG. Negative religious coping as a correlate of suicidal ideation in patients with advanced cancer. Psychooncology. 2014;23(8):936-45.

17. Spencer RJ, Ray A, Pirl WF, Prigerson HG. Clinical correlates of suicidal thoughts in patients with advanced cancer. Am J Geriatr Psychiatry. 2012; 20(4):327-36.

18. Recklitis CJ, Diller LR, Li X, Najita J, Robison LL, Zeltzer L. Suicide ideation in adult survivors of childhood cancer: a report from the childhood Cancer survivor study. J Clin Oncol. 2010;28(4):655-61.

19. Recklitis CJ, Lockwood RA, Rothwell MA, Diller LR. Suicidal ideation and attempts in adult survivors of childhood cancer. J Clin Oncol. 2006;24(24): 3852-7.

20. Walker J, Waters RA, Murray G, Swanson H, Hibberd CJ, Rush RW, Storey DJ, Strong VA, Fallon MT, Wall LR, et al. Better off dead: suicidal thoughts in cancer patients. J Clin Oncol. 2008;26(29):4725-30.

21. Handley TE, Inder KJ, Kay-Lambkin FJ, Stain HJ, Fitzgerald M, Lewin TJ, Attia JR, Kelly BJ. Contributors to suicidality in rural communities: beyond the effects of depression. BMC Psychiatry. 2012;12:105

22. Sullivan M, Rapp S, Fitzgibbon D, Chapman CR. Pain and the choice to hasten death in patients with painful metastatic cancer. J Palliat Care. 1997; 13(3):18-28.

23. Choi YN, Kim YA, Yun YH, Kim S, Bae JM, Kim YW, Ryu KW, Lee JH, Noh JH, Sohn TS. Suicide ideation in stomach cancer survivors and possible risk factors. Support Care Cancer. 2014;22(2):331-7.

24. Recklitis CJ, Zhou ES, Zwemer EK, Hu JC, Kantoff PW. Suicidal ideation in prostate cancer survivors: understanding the role of physical and psychological health outcomes. Cancer. 2014;120(21):3393-400.

25. Zhong BL, Li SH, Lv SY, Tian SL, Liu ZD, Li XB, Zhuang HQ, Tao R, Zhang W, Zhuo CJ. Suicidal ideation among Chinese cancer inpatients of general hospitals: prevalence and correlates. Oncotarget. 2017;8(15): 25141-50.

26. Fried El, Nesse RM. Depression sum-scores don't add up: why analyzing specific depression symptoms is essential. BMC Med. 2015;13:72.

27. Kleinman A. Culture and depression. N Engl J Med. 2004;351(10):951-3.

28. Yap AU, Chua EK, Tan KB. Depressive symptoms in Asian TMD patients and their association with non-specific physical symptoms reporting. J Oral Pathol Med. 2004;33(5):305-10.

29. Gustafson DH, McTavish FM, Stengle W, Ballard D, Hawkins R, Shaw BR, Jones $E$, Julesberg K, McDowell H, Chen WC, et al. Use and impact of eHealth system by low-income women with breast Cancer. J Health Commun. 2005;10(Suppl 1):195-218.

30. Schwarzer R, Renner B. Social-cognitive predictors of health behavior: action self-efficacy and coping self-efficacy. Health Psychol. 2000;19(5):487-95.
31. Merluzzi TV, Martinez Sanchez MA. Assessment of self-efficacy and coping with cancer: development and validation of the cancer behavior inventory. Health Psychol. 1997;16(2):163-70.

32. Finney Rutten LJ, Hesse BW, St Sauver JL, Wilson P, Chawla N, Hartigan DB, Moser RP, Taplin S, Glasgow R, Arora NK. Health self-efficacy among populations with multiple chronic conditions: the value of patient-centered communication. Adv Ther. 2016;33(8):1440-51.

33. Isaac V, Wu CY, McLachlan CS, Lee MB. Associations between health-related self-efficacy and suicidality. BMC Psychiatry. 2018;18(1):126.

34. Feng J, Li S, Chen H. Impacts of stress, self-efficacy, and optimism on suicide ideation among rehabilitation patients with acute pesticide poisoning. PLoS One. 2015;10(2):e0118011.

35. Latham AE, Prigerson $\mathrm{HG}$. Suicidality and bereavement: complicated grief as psychiatric disorder presenting greatest risk for suicidality. Suicide Life Threat Behav. 2004;34(4):350-62.

36. Cohen SR, Sawatzky R, Russell LB, Shahidi J, Heyland DK, Gadermann AM. Measuring the quality of life of people at the end of life: the McGill quality of life questionnaire-revised. Palliat Med. 2017;31(2):120-9.

37. Lev EL, Owen SV. A measure of self-care self-efficacy. Res Nurs Health. 1996; 19(5):421-9.

38. Lin J, Wang $X$, Dong F, Du Y, Shen J, Ding S, Wang L, Ye M, Wang Y, Xia N, et al. Validation of the Chinese version of the Hamilton rating scale for depression in adults with epilepsy. Epilepsy Behav. 2018;89:148-52.

39. Zimmerman M, Martinez JH, Young D, Chelminski I, Dalrymple K. Severity classification on the Hamilton depression rating scale. J Affect Disord. 2013; 150(2):384-8.

40. Tang GX, Yan PP, Yan CL, Fu B, Zhu SJ, Zhou LQ, Huang X, Wang Y, Lei J. Determinants of suicidal ideation in gynecological cancer patients. Psychooncology. 2016;25(1):97-103.

41. Zhang $X$, Zhang J, Procter $N$, Chen $X$, Su Y, Lou F, Cao F. Suicidal ideation and psychological strain among patients diagnosed with stomach Cancer: the mediation of psychopathological factors. J Nerv Ment Dis. 2017:205(7):550-7.

42. Kim YJ, Lee KJ. Relationship of social support and meaning of life to suicidal thoughts in cancer patients. J Korean Acad Nurs. 2010;40(4):524-32.

43. Akechi T, Nakano T, Akizuki N, Nakanishi T, Yoshikawa E, Okamura H, Uchitomi Y. Clinical factors associated with suicidality in cancer patients. Jpn J Clin Oncol. 2002;32(12):506-11.

44. Akechi T, Okamura H, Nakano T, Akizuki N, Okamura M, Shimizu K, Okuyama T, Furukawa TA, Uchitomi Y. Gender differences in factors associated with suicidal ideation in major depression among cancer patients. Psychooncology. 2010;19(4):384-9.

45. Silverman MM, Berman AL, Sanddal ND, O'Carroll PW, Joiner TE. Rebuilding the tower of babel: a revised nomenclature for the study of suicide and suicidal behaviors. Part 1: background, rationale, and methodology. Suicide Life Threat Behav. 2007;37(3):248-63.

46. Bernert RA, Kim JS, Iwata NG, Perlis ML. Sleep disturbances as an evidencebased suicide risk factor. Curr Psychiatry Rep. 2015;17(3):554.

47. Dombrovski AY, Butters MA, Reynolds CF 3rd, Houck PR, Clark L, Mazumdar S, Szanto K. Cognitive performance in suicidal depressed elderly: preliminary report. Am J Geriatr Psychiatry. 2008;16(2):109-15.

48. Roth $T$, Jaeger $\mathrm{S}$, Jin R, Kalsekar A, Stang PE, Kessler RC. Sleep problems, comorbid mental disorders, and role functioning in the national comorbidity survey replication. Biol Psychiatry. 2006;60(12):1364-71.

49. Philip EJ, Merluzzi TV, Zhang Z, Heitzmann CA. Depression and cancer survivorship: importance of coping self-efficacy in post-treatment survivors. Psychooncology. 2013;22(5):987-94.

\section{Publisher's Note}

Springer Nature remains neutral with regard to jurisdictional claims in published maps and institutional affiliations. 